\title{
PENDEKATAN KARAKTERISTIK RESPON GETARAN SISTEM 2 DOF SETELAH PENAMBAHAN INDEPENDENT DUAL TRANSLASIONAL DYNAMIC VIBRATION ABSORBER
}

\author{
Susastro $^{1, *}$, Novi Indah Riani ${ }^{2}$, Alaya Fadlu Hadi Muhammad ${ }^{3}$ \\ ${ }^{1,3}$ Sekolah Vokasi Universitas Diponegoro, Jalan Prof. H. Soedharto, S.H. Tembalang, \\ Semarang 50275 Indonesia \\ ${ }^{2}$ Jurusan Teknik Mesin, Institut Teknologi Adhi Tama Surabaya, Jalan Arif Rahman Hakim 100, \\ Surabaya 60111 Indonesia \\ "E-mail: susastro@live.undip.ac.id
}

Diterima: 24-01-2019

Direvisi: 20-02-2019

Disetujui: 01-06-2019

\begin{abstract}
ABSTRAK
Dual Translasional dynamic vibration absorber (dDVA) dua buah masa DVA yang dapat bergerak pada arah translasional dan diberikan pada sistem guna meredam getaran translasi- rotasi sistem. Penelitian terkait penggunaan dual translasional DVA untuk mengurangi getaran dengan metode simulasi telah dilakukan, namun belum ada kajian terkait penggunaannya metode eksperimental dalam penelitian tersebut guna melakukan hasil validari dari hasil simulasi yang dilakukan. Dalam penelitian ini dilakukan kajian terkait karakteristik response getaran sistem 2 DOF setelah penambahan dual translasional DVA dengan pendekatan eksperimental dan membandingkan hasilnya dengan data hasil simulasi. Perbandingan antara data hasil eksperimen dan simulasi dilakukan guna mengetahui tingkat error yang terjaidi antara kedua metode tersebut. Data hasil simulasi diperoleh dengan mensimulasikan kembali persamaan gerak yang ada dari studi literatur, seangkan data hasil eksperimen diperoleh melalui pengujian melalui alat uji DVA dengan dilakukan beberapa perubahan fekuensi eksitasi. Dari hasil penelitian ditunjukan karakteristik getaran hasil eksperimen adalah sama dengan karakteristi getaran hasil simulasi, dengan rata-rata tingkat segnifikansi sebesar $91,5 \%$. Adanya error yang terjadi antara hasil simulasi dan eksperimen lebih dikarenakan oleh tersalurnya sebagian getaran dari sistem utama kepada lingkungan di sekitar sestem, sehingga mengakibatkan adanya perbedaan hasil anara simulasi dan eksperimen.
\end{abstract}

Kata kunci: double dynamic vibration absorber, vibration, modeling

\section{ABSTRACT}

Dual Translational dynamic vibration absorber (dDVA) is two DVA masses that can move in the translational direction and given into the system to reduce system-translation translational vibrations. The research about using dual translational DVA to reduce vibration with the simulation method has been done, but a study about using the experimental method in that study to do validation from the simulation results that never been done. In this research we conducted a study related to the characteristics of 2 DOF system vibration response after the addition of dual translational DVA with an experimental approach and compared the results with simulation results data. Comparison between experiment date and simulation date is done in order to determine the level of error between the two methods. Simulation data is obtained by simulating the existing equations of motion from the study of literature, while the experimental data is obtained from testing with a DVA test with several changes in the frequency of excitation. From this research shows that the vibration characteristics of the experimental results are the same as the characteristics of the vibration of the simulation results, with an average significance level of $91.5 \%$. The error that occurs between the results of the simulation and experiment is caused by the disappearance of some vibrations from the main system to the environment around the system, so that resulting differences result between simulation and experiment.

Keywords: double dynamic vibration absorber, vibration, reduce vibration 


\section{PENDAHULUAN}

Kualitas dari desain alat sebagai contoh dalam desain pompa dan genset tidak hanya dinilai dari quality of conformance atau parameter operasionalnya, namun juga dari noise dan getaran yang timbul [1]. Timbulnya getaran yang terlalu berlebih tentu akan memberikan kerugian pada sistem terutama dalam hal kebisingan yang terlalu besar maupun life cycle yang lebih pendek. Oleh sebab itulah getaran yang berlebih perlu untuk dilakukan pengurangan. Salah satu cara mengurangi getaran sistem adalah dengan menambahkan dynamic vibration absorber. Dynamic vibration absorber merupakan masa dan pegas dengan konstanta tertentu yang diberikan pada sistem utama guna menciptakan antiresonansi pada getaran operasional dari sistem.

Keuntungan melakukan pengurangan getaran dengan DVA adalah tidak perlu dilakukannya perubahan desain mayor dari sistem utama yang telah di buat. Metode ini pertama kali diperkenalan oleh frahm [2] dan watts [3]. Kelebihan pengurangan getaran dengan metode ini adalah kita tidak perlu melakukan redesign pada alat yang telah dibangun [4].

Beberapa penelitian terkait dynamic vibration absorber sudah banyak dilakukan. Beberapa peneliti terkait penggunaan DVA telah memfokuskan diri pada penggunaan masa tambahan merupa magnet $[5,6]$. Untuk dapat meredam sistem denga dua derajat kebebsan juga telah dilakukan penelitian terkait penggunaan dynamic vibration absorber untuk meredam getaran 2 DOF [7-12]. terdapat beberapa metode dalam menambahkan dynamic vibration absorber guna mengurangi getaran pada sistem 2 DOF, diantaranya adalah dengan menambahkan variabel intertia [7], menggunakan sebuah masa translasional dynamic vibration absorber [8,9], maupun dengan memberikan dua buah translasional dynamic vibration absorber yang kemudian disebut sebagai dual translasional dynamic vibration absorber [10-12]. Penggunaan dual translasional DVA dilakukan dengan memberikan dual translasional DVA yang diberikan perubahan lengan momen yang sama besar satu sama lain [11], untuk mengetahui efek pengunaan dual translasional DVA dengan lengan momen yang berbeda antar kedua masa DVA, maka dilakukan penelitian lebih lanjut [12]. Namun penelitian yang dilakukan hanyalah sebatas simulasi sehingga perlu dilakukan validasi kebenaran dengan membandingkan antara hasil simulasi yang diperoleh dalam penelitian [12] dengan menggunakan prototype uji DVA.

Dalam penelitian ini dilakukan proses perbandingan antara hasil simulasi dan eksperimen dari efek penggunaan dependent dual translasional dynamic vibration absorber. data hasil simulasi diperoleh dengan mensimulasikan kembali persamaan matematika dari literatur yang ada ke dalam software numerik. Sedangkan data hasil eksperimen dioerileh dari pengambilan data secara eksperimen laboraturium.

\section{METODE PENELITIAN}

Dalam sebuah simulasi sudah tentu diperlukan persamaan gerak untuk kemudian disimulasikan. Dalam penelitian ini persamaan yang digunakan untuk simulasi diperoleh dari hasil studi literatur. Dari studi literatur diperoleh 4 buah persamaan gerak dan 2 buah persaman eksitasi. Adapun persamaan gerak yang digunakan yang digunakan ditunjukan sebagaimana persamaan 1 hingga 4 sebagai berikut.

$$
\begin{aligned}
& \ddot{y_{a 2}}=\frac{1}{M_{a}}\left[C_{a} \dot{y}_{s}-C_{a} d \dot{\theta}+k_{a} y_{s}-k_{a} d \theta-\right. \\
& \left.C_{a} y_{a 2}-k_{a} y_{a 2}\right] \\
& \ddot{y_{a 1}}=\frac{1}{M_{a}}\left[C_{a} \dot{y}_{s}+C_{a} c \dot{\theta}+k_{a} y_{s}+k_{a} c \theta-\right. \\
& \left.C_{a} y_{a 1}^{\cdot}-k_{a} y_{a 1}\right] \\
& \ddot{\theta}=\frac{1}{I}\left[\left(-C_{1} l_{1}+C_{2} l_{2}+C_{a} d+C_{a} c\right) \dot{y}_{s}+\right. \\
& \left(-k_{1} l_{1}+k_{2} l_{2}+k_{a} d+k_{a} c\right) y_{s}-C_{a} d \dot{y}_{a}- \\
& C_{a} c \dot{y}_{b}-k_{a} d y_{a}-\boldsymbol{k}_{a} c y_{b}-m b \omega^{2} R \sin (\alpha+ \\
& 90)+m a \omega^{2} R \sin (\alpha)-\left(C_{1} l_{1}{ }^{2}+C_{2} l_{2}{ }^{2}+\right. \\
& \left.C_{a} d^{2}-C_{a} c^{2}\right) \dot{\theta}-\left(k_{1} l_{1}{ }^{2}+k_{2} l_{2}{ }^{2}+k_{a} d^{2}-\right. \\
& \left.\left.k_{a} c^{2}\right) \theta\right]
\end{aligned}
$$

$\ddot{y}_{s}=\frac{1}{m_{s}}\left[m \omega^{2} R \sin \alpha+m \omega^{2} R \sin (\alpha+90)+\right.$ $C_{a} \dot{y}_{a}+C_{a} \dot{y}_{b}+k_{a} y_{a}+k_{a} y_{b}-\left(C_{1}+C_{2}+\right.$ 
$\left.2 C_{a}\right) \dot{y}_{s}-\left(k_{1}+k_{2}+2 k_{a}\right) y_{s}-\left(C_{1} l_{1}-\right.$

$\left.C_{2} l_{2}-C_{a} d+C_{a} c\right) \dot{\theta}-\left(k_{1} l_{1}-k_{2} l_{2}-k_{a} d+\right.$

$\left.\left.k_{a} c\right) \theta\right]$

Persamaan eksitasi yang bekerja dalam simulasi adalah berupa dua buah masa yang diputar dengan beda fasa sebesar $90^{\circ}$. Berdasarkan study literatur diperoleh 2 buah persamaan gerak seagaimana pada persamaan (5) dan (6).

$$
F=m \cdot \omega^{2} \cdot R \cdot \sin (\omega \cdot t)
$$

$F_{2}=m \omega^{2} R \sin (\alpha+90)$

Nilai parameter yang digunakan dalam simulasi merupakan parameter yang berasal dari penelitian terdahulu. Berdasarkan study literatur tersebut diperoleh parameter simulasi sebagai berikut:

Tabel 1. Parameter Simulasi

\begin{tabular}{ll}
\hline Parameter & Nilai \\
\hline$m_{s}$ & $13,88 \mathrm{Kg}$ \\
$m_{m}$ & $5 \mathrm{Kg}$ \\
$m_{k p}$ & $5 \mathrm{Kg}$ \\
$m$ & $0,14 \mathrm{Kg}$ \\
$m_{b}$ & $3,88 \mathrm{Kg}$ \\
$L$ & $0,53 \mathrm{m0}$ \\
$c$ & $0,06 \mathrm{~m}$ \\
$l_{2}$ & $0,145 \mathrm{~m}$ \\
$I$ &, $401 \mathrm{Kg} . \mathrm{m}^{2}$ \\
$k_{1}$ & $38.800 \mathrm{~N} / \mathrm{m}$ \\
$k_{2}$ & $38.800 \mathrm{~N} / \mathrm{m}$ \\
$c_{1}$ & $49,7 \mathrm{~N} . \mathrm{s} / \mathrm{m}$ \\
$c_{2}$ & $49,7 \mathrm{~N} . \mathrm{s} / \mathrm{m}$ \\
$c_{a}$ & $1,75 \mathrm{~N} . \mathrm{s} / \mathrm{m}$ \\
$a$ & $0,06 \mathrm{~m}$ \\
$l_{l}$ & $0,145 \mathrm{~m}$ \\
& \\
\hline
\end{tabular}

Dalam penelitian ini besar kedua masa absorber adalah sama besar, yaitu sebesar $\frac{1}{40}$ dari masa total sistem. Dengan demikian maka kekakuan absorber yang digunakan masingmasing juga sebesar $\frac{1}{40}$ dari kekakuan total sistem.

Simulasi dilakukan dengan menggunakan program pada numerikan software. Dalam simulasi dilakukan beberapa normalisasi yaitu Rasio frekuensi translasi (rf) dan Rasio frekuensi rotasi (rfr). Rasio frekuensi translasi (rf) merupakan hasil normalisasi frekuensi eksitasi terhadap frekuensi natural arah translasi. Rasio frekuensi rotasi (rfr) merupakan hasil normalisasi antara frekuensi eksitasi terhadap frekuensi arah rotasi sistem.

Untuk mempermudah proses pembandingan dengan hasil eksperimen maka lengan momen pada kedua masa absorber yang diberikan adalah sebesar nol, yang artinya bahwa kedua masa absorber terletak pada center of grafity dari sistem utama. Adapun frekuensi eksitasi divariasikan antara $0 \mathrm{~Hz}$ hingga $30 \mathrm{~Hz}$.

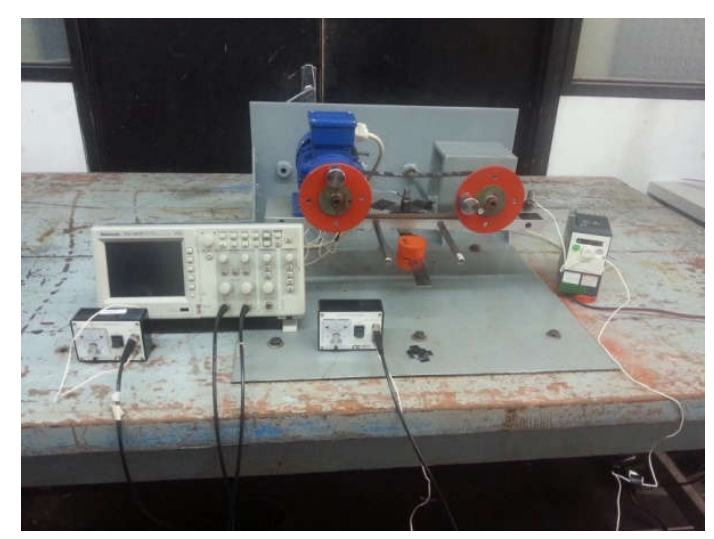

Gambar 1. Pengambilan data Secara Eksperimen

Untuk memvalidasi hasil simulasi yan dilakukan, maka selanjutnya dilakukan eksperimen untuk membandingkan besar error yang terjadi. Eksperimen dilakukan dengan mengambil data response getaran berupa akselerasi pada alat uji Dual translasional DVA sebagaimaa ditunjukan pada gambar 1 . pengambilan data dilakukan pada frekuensi 7 $\mathrm{Hz}$ hingga $21 \mathrm{~Hz}$. Data yang diperoleh kemudian di olah untuk memperoleh data berupa RMS percepatan pada setiap set point frekuensi. Hasil pengolahan data kemudiandilakukan perbandingan dengan grafik hasil RMS percepatan hasil simulasi untuk dilakukan analisa lebih lanjut.

\section{HASIL DAN PEMBAHASAN}

Dalam pembahasan kali ini dibahas perbandingan yang di peroleh dari RMS getaran sistem hasil simulasi terhadap eksperimen. Adapun RMS getaran sistem yang ditunjukan adalah ketika sistem tidak diberikan dual dynamic vibration absorber. Perbandingan dilakukan pada kedua arah sumbu gerak sistem, yaitu pada arah translasi maupun rotasi. Adapun grafik hasil 
perbandingan tersebut ditunjukan sebagaimana pada gambar 2 .

Gambar 2 (a) menunjukan perbandingan grafik RMS getaran translasi saat sistem tanpa diberikan dual dynamic vibrtion absorber. Grafik berwarna hitam menunjukan hasil simulasi, sedangkan titik-titik berwarna biru merupakan grafik hasil pengambilan data secara ekspermental. Secara umum bentuk tren grafik yang diperoleh dari hasil eksperimen ternyata sama dengan tren grafik yang diperoleh dari hasil simulasi. Meski memiliki bentuk tren yang sama antara hasil simulasi dan eksperimen, namun ternyata hasil analisa menunjukan rata-rata besar penyimpangan data yang cukup besar antara hasil eksperimen dan simulasi. Adapun besar penyimpangan data rata-rata yang diperoleh antara getaran hasil simulasi dan hasil eksperimen adalah sebesar $7,96 \%$. Besarnya penyimpangan ini dikarenakan adanya sebagian getaran dari sistem utama yang tersalurkan kepada lingkungan disekitar alat uji dual-DVA, khususnya dalam ini adalah meja tempat peletakan alat uji dual-DVA.

Saat sistem diberikan rasio frekuensi yang rendah kita dapat melihat bahwa besar penyimpangan yang terjadi antara RMS getaran translasi hasil simulasi dan eksperimen sangatlah kecil. Kecilnya penyimpangan ini dikarenakan saat diberikan frekuensi yang rendah, seluruh energi getar masih terfokus pada sistem utama sehingga tidak ada energi getar yang tersalurkan keluar kepada lingkungan. Namun ketika sistem diberikan rasio frekuensi yang mendekati frekuensi natural translasi $(\mathrm{rf}=1)$, terjadi penyimpangan nilai yang sangat besar antara RMS getaran translasi hasil simulasi dan eksperimen. Adapun penyimpangan terbesar yang terjadi adalah sebesar $50,11 \%$ sebagaimana ditunjukan pada gambar 3 (a).

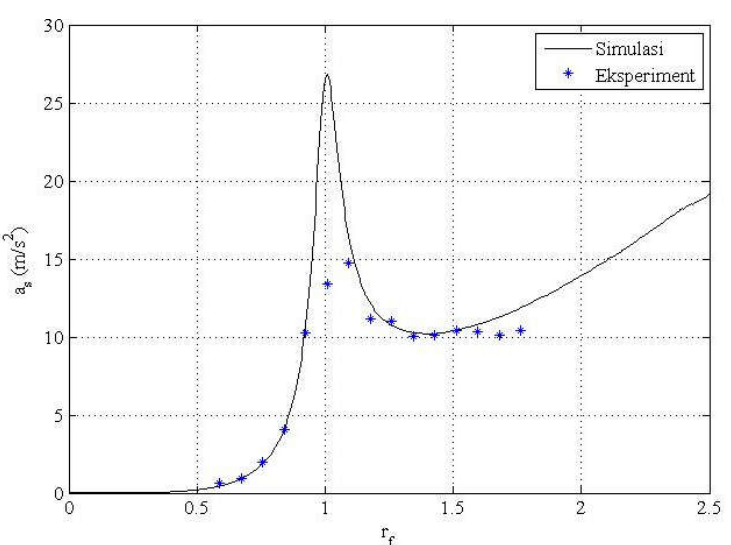

(a)

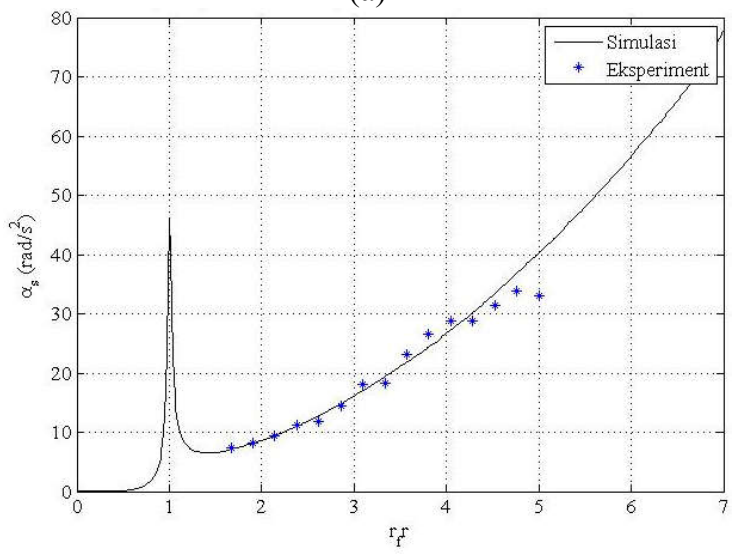

(b)

Gambar 2. Grafik perbandingan RMS getaran sistem dari hasil simulasi dan eksperimen (a) translasi tanpa dual DVA dan (b) rotasi tanpa dual DVA

Gambar 2 (b) menunjukan perbandingan grafik RMS getaran arah rotasi saat sistem tanpa diberikan dual dynamic vibrtion absorber. Grafik berwarna hitam menunjukan hasil simulasi, sedangkan titik-titik berwarna biru merupakan grafik hasil pengambilan data secara ekspermental. Secara umum bentuk tren grafik yang diperoleh dari hasil eksperimen ternyata sama dengan tren grafik yang diperoleh dari hasil simulasi.

Meski memiliki bentuk tren yang sama antara hasil simulasi dan eksperimen, namun ternyata berdasarkan hasil analisa lebih lanjut memperlihatkan adanya error yang terjadi antara data hasil simulasi dan data hasil eksperimen. Adapun prosentase error yang terjadi untuk setiap sampel data ditunjukan pada gambar 3 (b). Berdasarkan gambar tersebut menunjukan besar prosentase error yang terjadi pada sistem tanpa DVA adalah berkisar antara $0,77 \%$ hingga $17,78 \%$ dan ratarata error sebesar 5,45\%. 


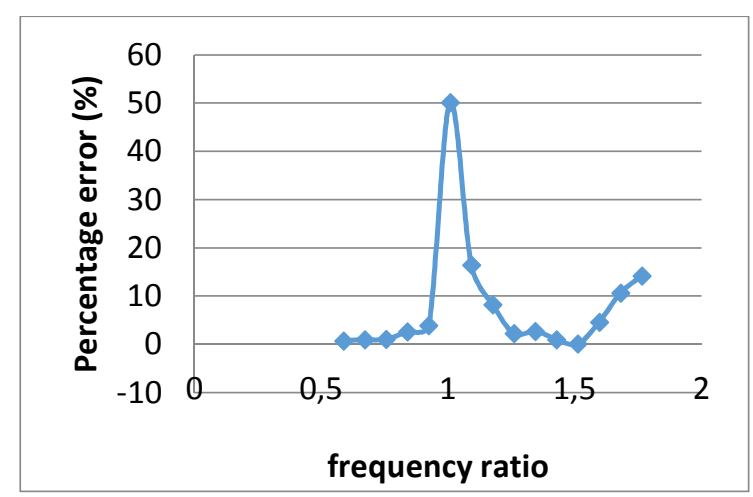

(a)

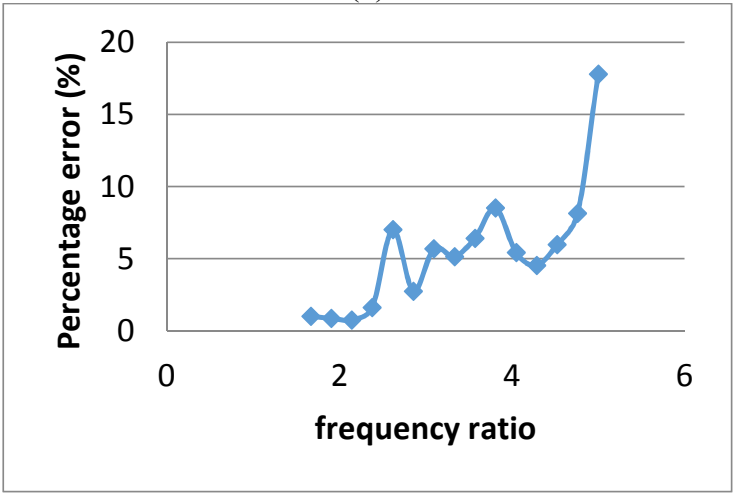

(b)

Gambar 3. Grafik prosentase perbedaan antara hasil simulasi dan eksperimen (a) translasi tanpa

dual DVA dan (b) rotasi tanpa dual DVA

Saat sistem diberikan rasio frekuensi yang rendah kita dapat melihat bahwa besar prosentase eror sangatlah kecil sebagaimana pada gambar 3 (b). Kecilnya penyimpangan ini dikarenakan saat diberikan frekuensi yang rendah, seluruh energi getar masih terfokus pada sistem utama sehingga tidak ada energi getar yang tersalurkan keluar kepada lingkungan. Semakin besar rasio frekuensi yang diberikan secara umum nilai prosentase error yang terjadi menjadi semakin besar. Semakin besarnya prosentase error ini dikarenakan adanya getaran yang tersalurkan kepada lingkungan disekitar alat uji, dalam hal ini adalah meja tempat diletakkanya alat uji DVA. Dengan tersalurkannya sebagian energi getaran sistem kepada lingkungan, maka berakibat pada berkurangnya getaran total yang terjadi pada sistem utama. Sehingga besar RMS getaran rotasi hasil eksperimen menjadi jauh lebih kecil dibandingkan RMS getaran rotasi hasil simulasi sebagaimana pada gambar 2(b). Dengan demikian terjadilah penyimpangan / error yang besar antara hasil simulasi dan eksperimen sebagaimana pada gambar 3 (b). Adapun error terbesar yang terjadi antara hasil smulasi dan eksperimen dalam kasus ini adalah sebesar 17,78\%.

Selanjutnya dibahas perbandingan yang di peroleh dari RMS getaran sistem hasil simulasi terhadap eksperimen. Adapun RMS getaran sistem yang ditunjukan adalah ketika sistem telah diberikan dual dynamic vibration absorber. Perbandingan dilakukan pada kedua arah sumbu gerak sistem, yaitu pada arah translasi maupun rotasi. Adapun grafik hasil perbandingan tersebut ditunjukan sebagaimana pada gambar 4 .

Gambar 4 (a) menunjukan perbandingan grafik RMS getaran translasi saat sistem dengan diberikan dual dynamic vibrtion absorber. Grafik berupa garis kontinu menunjukan hasil simulasi, sedangkan titik-titik berwarna biru merupakan grafik hasil pengambilan data secara ekspermental. Secara umum bentuk tren grafik yang diperoleh dari hasil eksperimen ternyata sama dengan tren grafik yang diperoleh dari hasil simulasi. Meski memiliki bentuk tren yang sama antara hasil simulasi dan eksperimen, namun ternyata hasil analisa menunjukan rata-rata besar penyimpangan data yang cukup besar antara hasil eksperimen dan simulasi. Adapun besar penyimpangan data rata-rata yang diperoleh antara getaran hasil simulasi dan hasil eksperimen adalah sebesar $13,38 \%$, dengan nilai error berkisar antara $3,37 \%$ hingga 34,82 . Besarnya penyimpangan ini dikarenakan adanya sebagian getaran dari sistem utama yang tersalurkan kepada lingkungan disekitar alat uji dual-DVA, khususnya dalam ini adalah meja tempat peletakan alat uji dual-DVA.

Saat sistem diberikan rasio frekuensi yang rendah kita dapat melihat bahwa besar penyimpangan yang terjadi antara RMS getaran translasi hasil simulasi dan eksperimen sangatlah kecil. Kecilnya penyimpangan ini dikarenakan saat diberikan frekuensi yang rendah, seluruh energi getar masih terfokus pada sistem utama sehingga tidak ada energi getar yang tersalurkan keluar kepada lingkungan. 


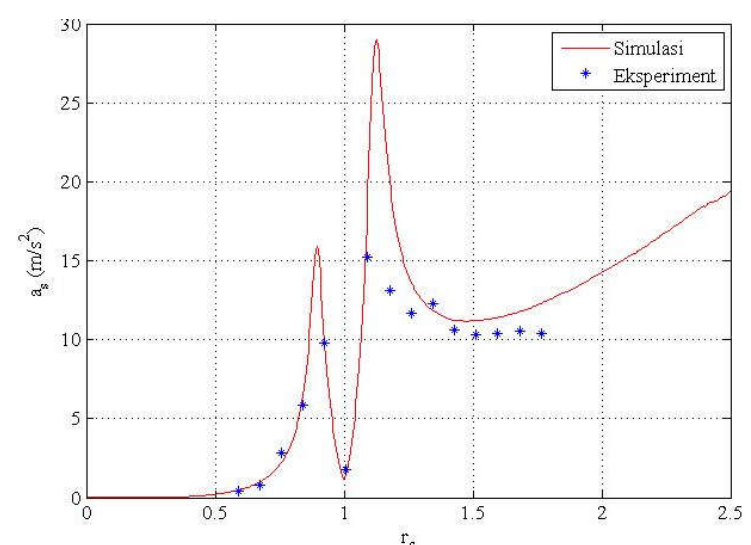

(a)

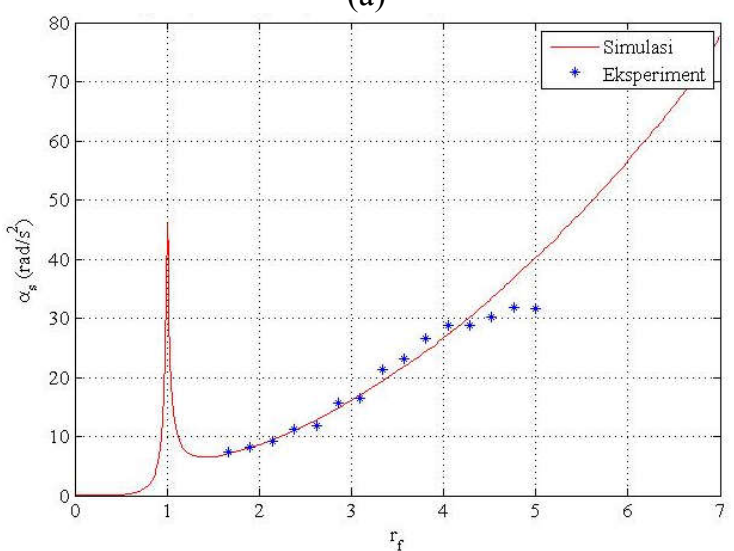

(b)

Gambar 4. Grafik perbandingan RMS getaran sistem dari hasil simulasi dan eksperimen (a) translasi dengan dual DVA dan (b) rotasi dengan dual DVA

Pemberian dual translasional dynamic vibration absorber pada posisi tengah dari beam berakibat pada bertambahnya jumlah frekuensi natural yang terjadi pada sistem. sistem yang awalnya hanya memiliki satu frekuensi natural berubah menjadi dua kali frekuensi natural. Apabila kita amati kembali pada gambar 5 (a) diperlihatkan bahwa ketika sistem diberikan frekuensi yang mendekati frekuensi natural berakibat pada semakin besarnya error yang terjadi. Kondisi ini ada dikarenakan saat frekuensi natural tercapai pada sistem maka energy getaran yang terjadi sangatlah tinggi. Besar energy getaran pada sistem tidaklah tersimpan secara sempurna pada sistem, melainkan tersalurkan kepada lingkungan disekitar dari sistem. Sebagai contoh adalah tersalurkan pada meja dimana alat uji DVA tersebut diletakkan. Hal inilah yang berakibat tingginya error saat frekuensi natural. Adapun besar error yang tertinggi berdasarkan data eksperimen yang dilakukan adalah sebesar $34,82 \%$.

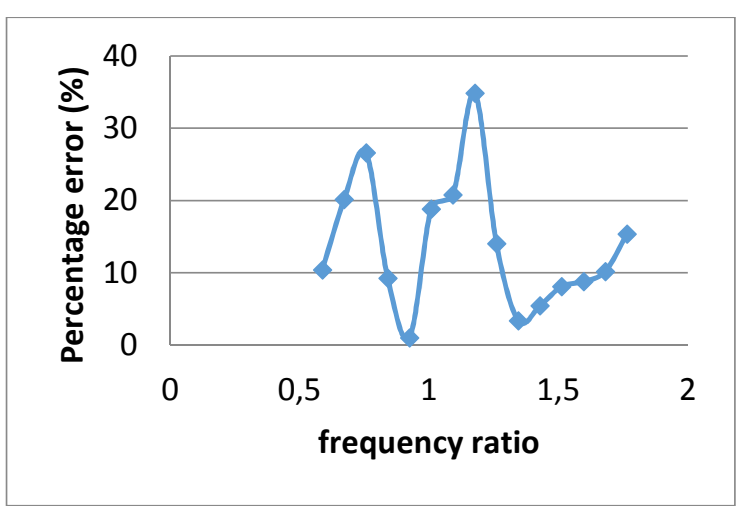

(a)

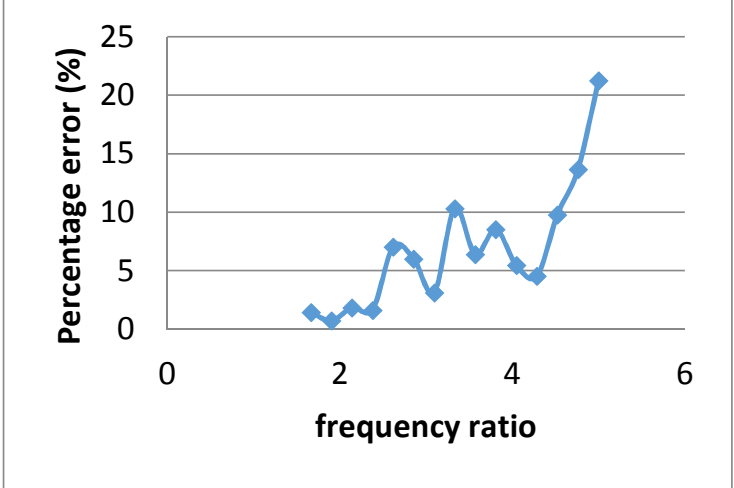

(b)

Gambar 5. Grafik prosentase perbedaan antara hasil simulasi dan eksperimen (a) translasi dengan dual DVA dan (b) rotasi dengan dual DVA

Peningkatan error pada saat tercapainya frekuensi natural sistm mungkin juga akan terjadi pada getaran arah rotasi, namun dalam penelitian ini pengambilan data dilaukan di atas frekuensi natural arah rotasi sebagaimana diperlihatkan pada gambar 4 (b). Dalam gambar tersebut terlihat bahwa secara umum grafik hasil eksperimen memiliki tren yang sama dengan grafik hasil simulasi. Saat frekuensi yang tinggi diperlihatkan bahwa penyimpangan antara hasil simulasi dan eksperimen menjadi semakin jauh, hal ini dipertegas dari grafik error data sebagaimana diperlihatkan pada gambar 5 (b). Adapun besar error terbesar yang terjadi adalah sebesar $21,26 \%$. Besar penyimpangan ini terjadi dikarenakan seluruh energi getaran sistem tidak tersimpan pada masa sistem utama, namun tersalurkan pada lingkungan di sekitar sistem, sehingga berakibat pada berkurangnya getaran hasil eksperimen.

Meski memiliki pengimpangan yang sangat tinggi saat diberikan frekuensi eksitasi yang tinggi, namun secara umum besar penyimpangan rata-rata yang terjadi antara 
grafik hasil simulasi dan eksperimen masih cukup rendah. Adapun besar penyimpangan antara data hasil simulasi adalah sebesar $6,78 \%$ yang menunjukan bahwa hasil simulasi dapat dikatakan sama dengan grafik hasil eksperimen.

\section{KESIMPULAN}

Dari keempat kondisi pada penelitian ini diperoleh nilai rata-rata error yang terjadi antara data hasil simulasi dan eksperimen adalah sebesar $8,5 \%$ saja. Dengan demikian juga dapat diartikan bahwa tingkat segnifikansi antara data hasil simulasi dengan data hasil eksperimen dalah sebesar 91,5\%. Kondisi ini menunjukan bahwa hasil simulasi yang dilakukan masih dapat dikatakan sama dengan hasil eksperimen (valid). Adanya error yang terjadi antara hasil simulasi dan eksperimen lebih dikarenakan oleh tersalurnya sebagian getaran dari sistem utama kepada lingkungan di sekitar sestem, sehingga mengakibatkan adanya perbedaan hasil anara simulasi dan eksperimen.

\section{DAFTAR PUSTAKA}

[1] Galezia, A. "Parameter Determination of Dynamic Vibration Absorber for Application in Household Equipment". Machine Dynamic Research. Vol. 40, pp 83-94, 2016

[2] Frahm, H., "Device for damping vibrations of bodies"U.S. Patent No. 989958, 1909.

[3] Watts, P., "On a method of reducing the rolling of ship at sea", Transactions of the Institute of Naval Architects, Vol. 24, pp. 165-190, 1883.

[4] Hartog, J. P. den, Mechanical Vibrations, McGraw-Hill, 1956

[5] Salem, M.H., "Performance of a dynamic vibration absorber using a magnetorheological damper", (2012) International Review of Mechanical Engineering (IREME), 6 (6), pp. 1146-1156

[6] Salem, M.H., "Control of a Dynamic Vibration Absorber Using a MagnetoRheological Damper," (2013) International Review of Mechanical Engineering (IREME), 7 (1), pp. 1146-1156

[7] Megahed, S.M. and AbdEl-Razik, A.K., "Vibration control of two degrees of freedoms system using variable inertia vibration absorbers: Modeling and simulation," Design and Production Department, Faculty of Engineering, Cairo University, Giza 12613, 2010.

[8] Aida Annisa Amin Daman. 2016. The influence of dynamic vibration absorber to reduce vibration of main system with 2-DOF. IECC.

[9] Susastro. "Optimasi Posisi dari Masa SDVA untuk Mereduksi Getran Translasi-Rotasi pda Beam". ITP Journal. Pp 39-44.

[8] Sun.H.L. 2008. Application of dynamic vibration absorber in structur vibration control under multi frequency harmonics excitation. Applied acoustics. Pp 1361-1367

[10] Kusumadewayanti. Esthi. 2015. Study pengaruh masa dan perubahan lengan momen dual dynamic vibration absorber (DVA)Independent terhadap respon getaran sistem utama - 2 DOF. Seminar nasional teknik mesin petra DS28-DS34.

[12] Susastro. "Optimizing vibration reduction in 2 dof system with change position of independent translational dual-dynamic vibration absorber". International Journal of Mechanical Engineering and Technology. Pp 882-892. 